\title{
European scientists push spinal taps for Alzheimer diagnosis
}

Tapping spinal fluid may yield early evidence of Alzheimer disease, years before clinical symptoms appear. Based on this premise, which is supported by increasing evidence, European scientists are pushing to use the test to distinguish the disease from other types of dementia and to help validate therapies.

The brain of an Alzheimer disease sufferer is marked by intracellular tangles composed of tau protein and abnormal extracellular clumps_-or plaques — of beta-amyloid protein.

In recent years, scientists have tried to assess whether there is also a relationship between the amount of beta-amyloid in the spinal fluid, where it is more abundant than in other body fluids, and Alzheimer disease.

Several studies have indicated that there is an inverse relationship between levels of the protein in the brain and in spinal fluid: the more betaamyloid in the brain, the lower the levels in spinal fluid. Mouse models of the disease have shown a similar association (J. Neurosci. 21, 372-381; 2001 and J. Neurochem. 81, 229-236; 2002).

The latest human study, published in December, is the first to confirm this relationship in living brains (Ann. Neurol.published online 21 December 2005, doi:10.1002/ana.20730). With only 24 individuals, the study, which used positron emission tomography, is small. But intriguingly, 3 study participants who had appeared normal —on tests that gauge memory, attention and problem-solving skills_-also showed signs

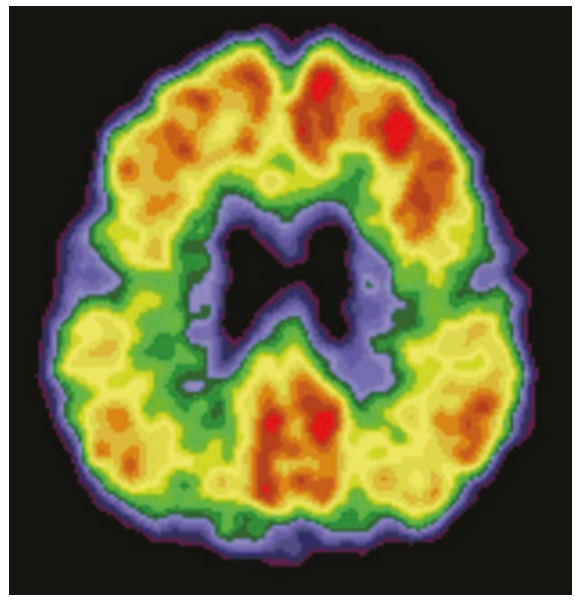

Bleak picture: Imaging techniques show amyloid plaques in an Alzheimer-addled brain.

of the disease as gauged by the spinal test.

"That was compelling," says lead investigator Anne Fagan, associate professor of neurology at Washington University in St. Louis. "It suggests that the tests can detect preclinical disease."

Fagan's study builds on data from Europe linking levels of three key proteins in the spinal fluid to Alzheimer disease. In December, Swedish researchers showed that observed together, abnormal levels of the proteins beta-amyloid, tau and a phosphorylated version of tau can distinguish Alzheimer disease from other types of dementia with an accuracy of more than $90 \%$ (Exp. Neurol. 196, 273-281; 2005).
In the largest study yet to assess spinal fluid as a diagnostic tool for Alzheimer disease, researchers are analyzing samples from nearly 1,000 individuals with mild cognitive impairment and early dementias. Preliminary results confirm the Swedish findings, says lead researcher Jens Wiltfang.

The data also suggest that the biomarkers can pick up the disease up to five years before clinical Alzheimer symptoms appear. Catching the disease early could help slow the logjam of plaques and tangles in the brain. "Any therapeutic diseasemodifying strategy is going to rely on early intervention," says Wiltfang, a member of the German Competence Network Dementia, a consortium of 14 national universities launched in 2002 to develop diagnostic tools for Alzheimer disease.

The US National Institute on Agingalong with more than a dozen US federal and private-sector organizations-has also launched a five-year $\$ 60$ million initiative to try and pinpoint early changes that lead to an Alzheimer-addled brain.

Without an effective way to track the disease, companies have found it challenging to prove that their drug can stall the disease, says Neil Buckholtz, chief of dementias at the institute. Spinal fluid tests could help drug development, he says, but "there needs to be more validation of these techniques and we need to follow larger numbers of people over time."

Gunjan Sinha, Berlin

\section{Australia considers changing laws to allow therapeutic cloning}

A government-commissioned review of Australia's stem cell research has recommended changes to the country's laws to allow therapeutic cloning. But experts predict that the final decision is unlikely until the nation's members of parliament vote on the issue later this year.

Australia's existing laws, introduced in 2002 , permit the creation of new stem cell lines from excess embryos created during in vitro fertilization, but placed a moratorium on therapeutic cloning, or creating embryos for research purposes. The government then promised to review the law after three years.

In June 2005, the government appointed a committee of six members to review the law in view of scientific developments and community attitudes about the field. The committee's report, released on 19 December, recommends lifting the moratorium on therapeutic cloning. It also proposes creating a national stem cell bank and says that scientists should be allowed to create crossspecies hybrids, in which animal eggs are used to reprogram human cells, for research purposes.

Scientists have welcomed the report, saying a change in the law would provide a muchneeded boost to Australian science. "We have felt excluded from the area and it's had a big impact on morale. It has been difficult to attract senior researchers," says Alan Trounson, a reproductive biologist at Monash University in Melbourne.

The restrictive laws have at least in part prompted some scientists to seek a more permissive environment. Peter Mountford, chief executive of the UK-based biotechnology firm Stem Cell Sciences, says the UK's favorable legislative environment was one of the reasons he decided to move the company's headquarters from Australia to Edinburgh. Monash University's Martin Pera is leaving in April to lead the newly created
Institute for Stem Cell and Regenerative Medicine at the University of Southern California.

But opponents of therapeutic cloning say the committee did not take the ethical considerations enough into account.

"The recommendations read like a wish list for researchers," says Frank Brennan, a professor of law at the Australian Catholic University and University of Notre Dame in Sydney. Loosening the law is unjustified given the limited progress of the therapeutic cloning, Brennan says. "It would allow a more permissive environment in ethical terms than what the technology warrants."

The previous stem cell laws followed a rare conscience vote, where members of parliament are given the opportunity to vote free of the direction or majority of their political party. Observers say it is likely they will repeat that process with the revisions.

Carina Dennis, Sydney 